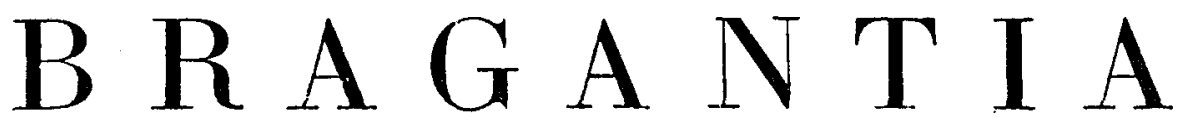

Boletim Científico do Instituto Agronômico do Estado de S. Paulo

Vol. 31

Campinas, janeiro de 1972

N. ${ }^{\circ} 8$

\title{
EMPREGO DE DOLICHOS LABLAB L. COMO ADUBO VERDE. I - ESTUDO DO PLANTIO INTERCALADO NA CULTURA DO MILHO $\left({ }^{1}\right)$
}

Luiz A. C. Lovadini $\left({ }^{2}\right)$, H. A. A. Mascarenhas $\left({ }^{2}\right)$, Shiro Miyasaka $\left({ }^{2}\right)$, engenheiros-agrônomos, Seção de Leguminosas, Toshio Igue $\left({ }^{2}\right)$, engenheiro-agrônomo, Seção de Técnica Experimental e Cálculo, Francisco I. Pastana, engenheiroagrônomo, Seção de Conservação do Solo, Instituto Agronômico, Clóvis Nery e Carlos Ricardo P. Laun, engenheitosagrônomos, Estação Experimental de São Simão, Ministério da Agricultura $\left({ }^{3}\right)$

\section{SINOPSE}

Em trabalho conduzido durante cinco anos, em várias localidades do Estado de São Paulo, foi estudada a consorciação das culturas de milho e lablab (Dolichos lablab L.), com relação ao efeito da época e do sistema de plantio, bem como a proporção das duas plantas, na prođução de milho em grãos. A consorciação das duas culturas não alterou significativamente a produção de milho.

Quando plantado na mesma época do milho, o lablab, devido à quantidade da massa verde, provocou, em alguns casos, acamamento e dificuldades na colheita.

\section{1 - INTRODUÇÃO}

Diversos estudos têm mostrado efeitos benéficos da adubação verde, tanto na melhoria das propriedades físicas do solo como no rendimento das colheitas. Esse tipo de adubação traz maiores benefícios quando é utilizada uma leguminosa $(1,2)$, que, além de outros efeitos, pode acrescentar ao solo certa quantidade de

( ) Recebido para publicação em 26 de agosto de 1971.

${ }^{2}$ ) Com bolsa de suplementação do CNPq.

${ }^{3}$ ) Os autores agradecem a colaboração dos Chefes das estações experimentais de Tietê, Ribeirăo Preto, Pindorama e Mococa, do Instituto Agronômico, e da de Botucatu, do Minıstério da Agricultura. 
nitrogênio. Trabalhos realizados anteriormente $(\mathbf{2}, \mathbf{4})$ mostraram que o emprego de Crotalaria juncea L. e da mucuna preta (Styzolobium atterrimum Pip. et Fracc.) como adubos verdes provocou efeitos benéficos nas produções de feijão e milho.

Recentemente foi introduzido pela Seção de Leguminosas, do Instituto Agronômico do Estado de São Paulo, um cultivar de Dolichos lablab L., de sementes brancas, o qual além de apresentar alta produção de massa verde pode ser plantado tardiamente, isto é, até fevereiro (3), sem o inconveniente de infestar a área plantada, como acontece com a mucuna preta.

Levando em consideração as características dessa planta, procurou-se estudar a possibilidade de efetuar seu plantio intercalado na cultura do milho. Esse sistema permitiria efetuar a adubação verde, ao mesmo tempo em que se explora uma cultura econômica, evitando, assim, ocupar o terreno durante um ano agrícola apenas com leguminosas. Permitiria também obter informações sobre a produção de massa verde da leguminosa que seria utilizada na seca, como pasto de inverno para os animais.

\section{2 - MATERIAL E METODOS}

Os ensaios foram planejados para serem executados durante cinco anos, nas seguintes localidades: São Simão e Botucatu, em estações experimentais do Ministério da Agricultura, Tietê, Ribeirão Preto e Mococa, em estações experimentais do Instituto Agronômico do Estado de São Paulo.

O plano experimental obedeceu a um esquema em blocos ao acaso, com oito tratamentos e seis repetições.

Os tratamentos constaram do plantio do lablab (Dolichos lablab L. v. 697) em diferentes épocas e proporções, intercalado na cultura do milho.

Em todos os tratamentos o milho foi sempre plantado em meados de outubro, utilizando-se duas sementes por cova, no espaçamento de 1 metro entre linhas e $20 \mathrm{~cm}$ dentro das linhas.

Nos tratamentos B, C, D o lablab foi semeado no mesmo dia do plantio do milho, nas mesmas linhas, nas mesmas covas (duas 
sementes por cova), pulando-se, respectivamente, uma, duas e três covas de milho. Nos tratamentos restantes $(\mathbf{E}, \mathbf{F}, \mathbf{G}, \mathbf{H})$, o lablab foi semeado em covas (duas sementes por cova), distanciadas de $60 \mathrm{~cm}$ nas entrelinhas do milho, respectivamente em novembro, dezembro, janeiro e fevereiro. No tratamento $\bar{A}$ foi semeado apenas o milho adubado.

$\mathrm{Na}$ relação a seguir encontram-se discriminados os tratamentos utilizados:

\section{A - Milho}

\begin{tabular}{|c|c|c|c|c|c|c|c|}
\hline B - & Milho & adubado + & lablab & (outubro) & nas & linhas & $1: 1$ \\
\hline C - & $"$ & $"$ & $"$ & " ) & $"$ & $"$ & $2: 1$ \\
\hline - & $"$ & $"$ & $"$ & $" \quad)$ & $"$ & $"$ & $3: 1$ \\
\hline- & $"$ & $"$ & " & (novembro) & \multicolumn{2}{|c|}{ " entrelinhas } & $: 1$ \\
\hline & $"$ & " & $"$ & (dezembro) & 9 & $"$ & \\
\hline & $"$ & $"$ & $"$ & (janeiro) & $"$ & $"$ & \\
\hline 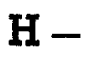 & $"$ & $"$ & $"$ & (fevereiro) & $"$ & $"$ & \\
\hline
\end{tabular}

O milho foi adubado com $400 \mathrm{~kg} / \mathrm{ha}$ da mistura 60:60:30. Aos 40 dias foram aplicados em cobertura $250 \mathrm{~kg} / \mathrm{ha}$ de sulfato de amônio. $O$ fósforo foi empregado na forma de superfosfato simples, e o potássio, como cloreto.

As parcelas constaram de seis linhas de milho de 10 metros de comprimento, considerando-se para a análise dos resultados apenas as produções de plantas das 4 linhas centrais.

Para o milho os tratos culturais foram os recomendados para essa cultura.

A produção de massa verde de lablab foi avaliada em julho, sendo pesada e devolvida para as respectivas parcelas.

Após a colheita do milho, a área experimental foi deixada em pousio, incorporando-se os restos vegetais pouco antes do plantio seguinte. As experiências se repetiram sempre sobre as mesmas parcelas. 


\section{3 - EXECUÇÃO E RESULTADOS}

A experiência de Mococa foi desprezada para análise, uma vez que as observações sobre produção de massa verde de lablab não foram realizadas.

\section{1 - ENSAIO DE SÃO SIMÃO}

Nos cinco anos desse ensaio, instalado numa parcela de Latossolo Roxo (5), da Estação Experimental de São Simão, do Ministério da Agricultura, o milho foi levemente atacado por lagartas, as quais foram combatidas com DDT. No ano agrícola de 1962/63 houve certo prejuízo para o milho, nos tratamentos consorciados com lablab, devido a fortes ventos ocorridos na ocasião, provocando acamamento, em virtude da barreira formada pela massa do lablab sobre as plantas de milho.

No ano agrícola de 1963/64, os restos de lablab do ano anterior parecem ter prejudicado a germinação do milho.

Nos tratamentos onde o lablab foi plantado em outubro, a concorrência com o milho já cra evidente em dezembro. Esse fato ocorreu durante os cinco anos nos quais se repetiu a experiência.

Nos tratamentos E, F, G, H, onde o lablab foi plantado mais tarde, a quantidade de massa verde produzida foi pequena. Os dados de produção de massa verde podem ser observados no quadro 1.

A análise de variância para a produção de massa verde mostrou, em todos os anos, diferenças altamente significativas entre tratamentos. Pelo teste de Tukev, a 5\% os tratamentos plantados em outubro não diferiram entre si, e foram maiores as suas produções.

A análise de variància para produção de milho mostrou diferenças significativas a $1 \%$ de probabilidade, e o teste de Tukey a $5 \%$ não mostrou diferenças significativas entre as médias dos tratamentos. Esses resultados podem ser vistos no quadro 2. 


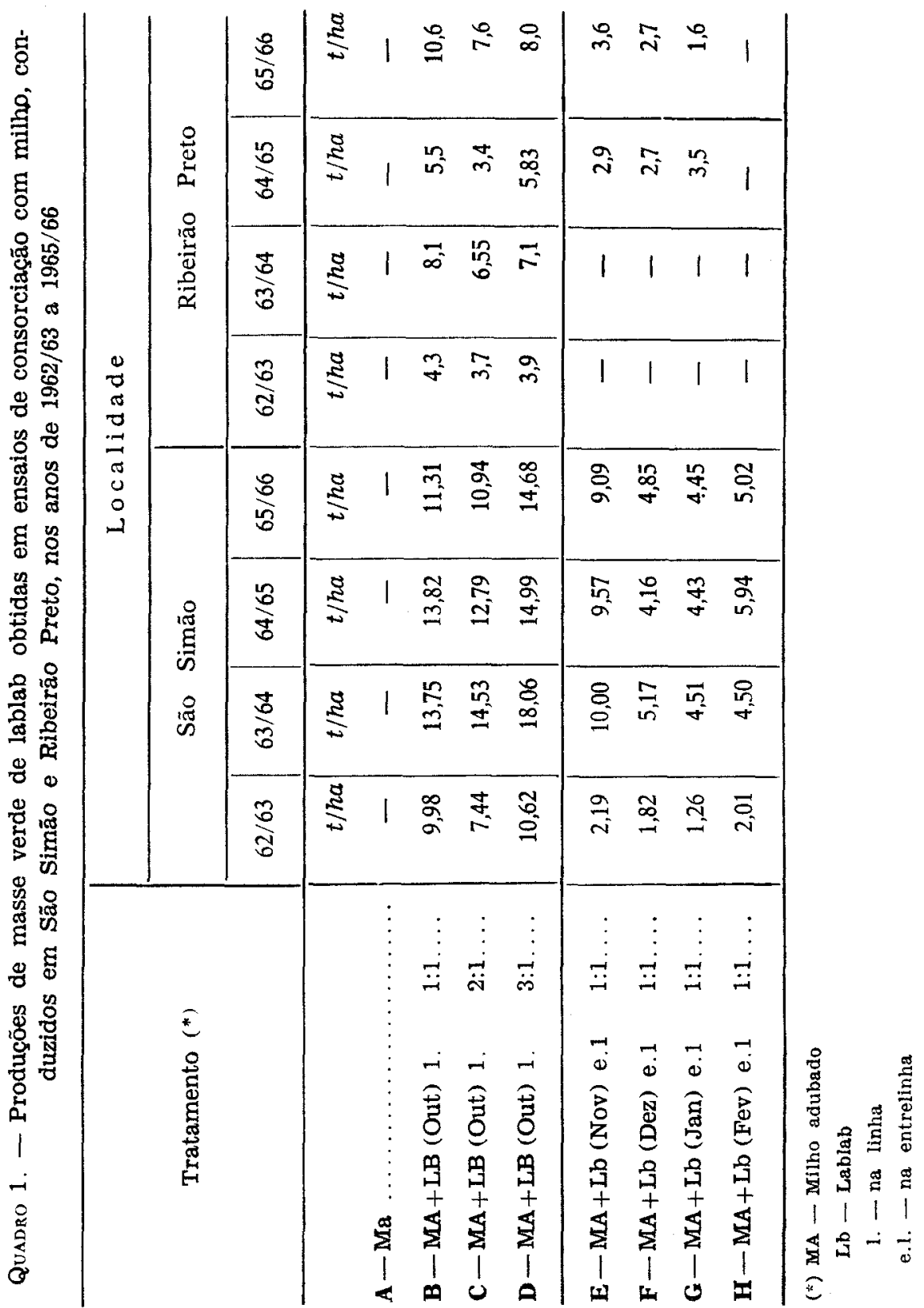


Examinando os dados médios de produção de milho dos cinco anos do experimento, verifica-se que não houve efeito do lablab como adubo verde, uma vez que a quantidade de massa verde incorporada foi pequena, mesmo nos tratamentos onde a produção da leguminosa foi maior.

Por outro lado parece ter havido certa concorrência do lablab com o milho, como mostram os dados do quadro 2. Os tratamentos que receberam a leguminosa produziram menos que o tratamento onde foi plantado apenas milho adubado, muito embora as diferenças não tenham sido significativas.

O lablab plantado tardiamente produziu quantidade menor de massa verde. Nos tratamentos em que o lablab foi plantado na mesma ocasião que o milho a maior proporção de leguminosas não produziu maior quantidade de massa verde.

Quadro 2. - Produções médias de milho, obtidas em diferentes localidades para os tratamentos indicados, numa série de ensaios realizados em 5 anos consecutivos - 1962/63 a $1966 / 67$

\begin{tabular}{|c|c|c|c|c|c|c|}
\hline \multirow{2}{*}{ Tratamento (*) } & & \multicolumn{5}{|c|}{ Localidade } \\
\hline & & $\begin{array}{c}\text { São } \\
\text { Simão }\end{array}$ & $\begin{array}{l}\text { Rib. } \\
\text { Preto }\end{array}$ & $\begin{array}{l}\text { Botu- } \\
\text { catu }\end{array}$ & $\begin{array}{l}\text { Pindo- } \\
\text { rama }\end{array}$ & Média \\
\hline & & $k g / h a$ & $k g / h a$ & $k g / h a$ & $k g / h a$ & $k g / h a$ \\
\hline $\mathbf{A}-\mathbf{M a} \ldots \ldots \ldots \ldots$ & $\cdots$ & 3713 & 5093 & 3968 & 3585 & 4324 \\
\hline$B-M A+L B($ Out) 1 & $1: 1$ & 2922 & 4154 & 3946 & 3049 & 3896 \\
\hline$C-M A+L B($ Out) 1 & $2: 1$ & 3402 & 4322 & 3919 & 3455 & 4083 \\
\hline D-MA+LB (Out) 1 & $3: 1$ & 3174 & 4592 & 4164 & 3465 & 4190 \\
\hline$E-M A+L b(N o v)$ e. 1 & $1: 1$ & 3348 & 4914 & 4057 & 3556 & 4278 \\
\hline $\mathbf{F}-\mathbf{M A}+\mathrm{Lb}(\mathrm{Dez})$ e.1 & $1: 1$ & 3554 & 4526 & 3922 & 3499 & 4200 \\
\hline$G-M A+L b(\operatorname{Jan})$ e.1 & $1: 1$ & 3479 & 4875 & 4294 & 3668 & 4346 \\
\hline $\mathbf{H}-\mathrm{MA}+\mathrm{Lb}(\mathrm{Fev})$ e.1 & $1: 1$ & 3394 & 4845 & 4210 & 3675 & 4285 \\
\hline
\end{tabular}

(*) MA - Milho adubado

Lb - Lablab

1. - na linha

e.1. - na entrelinha 


\section{2 - ENSAIO DE RIBEIRÃo PRETO}

Foi instalado numa parcela de Latossolo Roxo (5), da Estação Experimental de Ribeirão Preto.

Os dados de produção de milho, nos cinco anos agrícolas, estão resumidos no quadro 2 .

No ano agrícola de 1963/64 houve certo prejuízo na produção, em virtude da deficiência hídrica ocorrida na ocasiāo. Nos anos agrícolas de 1962/63 e 1963/64 não houve produção de massa verde de lablab, nos tratamentos $\mathbf{E}, \mathbf{F}, \mathbf{G}, \mathbf{H}$, plantados em novembro, dezembro e janeiro. Nos outros anos a produção foi pequena (quadro 1). Apenas nos tratamentos $\mathbf{B}, \mathbf{C}$ e $\mathbf{D}$, em que a leguminosa foi plantada em outubro, junto com o milho, houve produção razoável de massa verde, sendo que neste caso ela se mostrou invasora sobre o milho.

Nessa séric de experimentos não pôde ser efetuada a análise estatística, uma vez que a produção de massa verde do lablab foi prejudicada, e a principal finalidade dos experimentos era estudar o efeito da massa verde da leguminosa sobre a produção do milho c a concorrência entre as plantas.

Observou-se que nessa localidade o lablab quando plantado tardiamente tem seu desenvolvimento muito prejudicado, apenas conseguindo pequena produção quando plantado juntamente com o milho (quadro 1).

Nos tratamentos em que o lablab foi plantado em maior proporção em relação ao milho não houve aumento da produção de massa verde.

\section{3 - ENSAIO DE BOTUCATU}

Foi conduzido numa parcela de Latossolo Roxo (5), da Estação Experimental de Botucatu, do Ministério da Agricultura.

Como se pode observar pelo quadro 3, apenas nos tratamentos B, C e D, em que o lablab foi plantado na mesma ocasião do milho, houve produção considerável de massa verde. Nos tratamentos $\mathbf{E}$, F, G, $\mathbf{H}$ a leguminosa não conseguiu desenvolver-se suficientemente. 
Nos tratamentos B, C, D, em que o lablab foi plantado na mesma época que o milho, observou-se certa invasão da leguminosa sobre o milho, tanto mais intensa quanto maior a produção de massa verde. Nesses tratamentos, quando da ocorrência de chuvas pesadas, houve acamamento das plantas de milho, sob o peso da massa de lablab.

A análise da variância conjunta, para a produção de milho dos cinco anos, apresentou coeficiente de variação de $17,7 \%$. Mostrou, também, efeito significativo, ao nível de $1 \%$ de probabilidade, para tratamentos, anos e para a interação anos $\mathrm{x}$ tratamentos.

Todavia, as médias dos tratamentos não são comparáveis, uma vez que não houve produção de massa verde de lablab nos tratamentos E, F, G, H, no ano agrícola de 1962/63, e que foi irrisória nos outros anos.

Mesmo nos tratamentos em que a leguminosa se desenvolveu satisfatoriamente não foi notado nenhum efeito do adubo verde, uma vez que a quantidade de massa incorporada foi pequena. Nesses tratamentos não houve prejuízo ou concorrência do lablab com o milho, como podemos observar pelas respectivas produções, no quadro 2.

A maior produção da leguminosa em relação ao milho não acarretou maior produção de massa verde (quadro 3).

\section{4 - ENSAIO DE PINDORAMA}

Instalado numa parcela de solo Podzolizado de Lins e Marília, var. Marília (5) , da Estação Experimental de Pindorama.

O quadro 2 apresenta as produções de milho, obtidas nos cinco anos do ensaio. Observa-se que no ano agrícola de 1963/64 as produções de milho foram baixas, devido à deficiência hídrica ocorrida na época do florescimento.

Nos tratamentos B, C, D, em que o lablab foi plantado junto com o milho, observou-se boa produção de massa (quadro 3), sendo que, neste caso, a leguminosa mostrou-se invasora, formando uma barreira sobre as plantas de milho. 


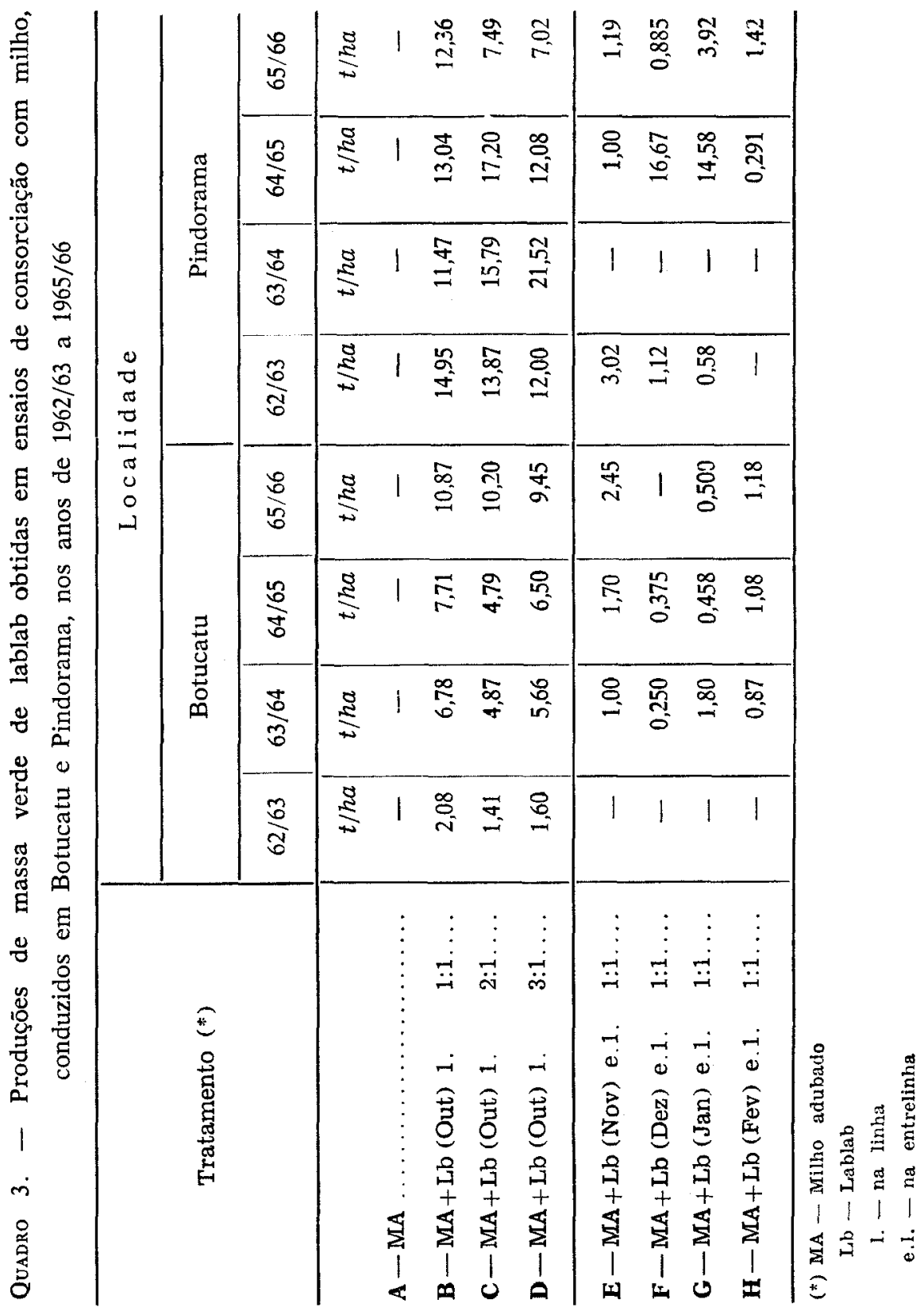


Não foi possível executar a análise da variância para os anos agrícolas de 1962/63 e 1963/64, sendo que nesses anos, nos tratamentos $\mathbf{E}, \mathbf{F}, \mathbf{G}, \mathbf{H}$, não houve produção satisfatória de massa verde de lablab.

A análise da variância para o ano agrícola de 1964/65 mostrou diferenças significativas a $1 \%$ de probabilidade, para tratamentos. Todavia, o teste de Tukey, a $5 \%$ de probabilidade, não conseguiu indicar diferenças entre as médias dos tratamentos, devido ao alto coeficiente de variação.

No ano agrícola de 1965/66 não foi cncontrada diferença significativa entre os tratamentos, pela análise de variância.

Pelos dados do quadro 3 observa-se que o lablab deve ser plantado na mesma ćpoca que o milho, pois os plantios tardios, de acordo com as condições do ano, poderão não produzir massa verde, e a produção será pequena.

Se forem examinadas as produções de milho dos anos de 1964/65 e de 1965/66 verificar-se-á que não houve efeito do lablab como adubo verde, quando plantado em consorciação com o milho, e que nem a maior proporção de leguminosa e a época de plantio influiram na produção do milho.

\section{4 - ESTUDO CONJUNTO DOS ENSAIOS}

A análise em conjunto de todos os anos agrícolas para as quatro localidades demonstrou que nos tratamentos $\mathbf{E}, \mathbf{F}, \mathbf{G}, \mathbf{H}$, em que respectivamente o lablab foi plantado em novembro, dezembro, janeiro e fevereiro, na maioria dos ensaios cle não conseguiu desenvolver-se, e quando o conseguiu, a produção foi pequena, devido ao sombreamento do milho e à concorrência em nutrientes. Apenas em São Simão a leguminosa se desenvolveu em todos os ensaios.

Como era de esperar, as produçõcs de milho desses tratamentos não diferiram entre si e nem da testemunha (milho adubado).

Nos tratamentos B, C, D, em que o lablab foi plantado na mesma época que o milho, a leguminosa desenvolveu-se razoavelmente, apresentando boa produção. Todavia, a maior proporção de 
leguminosa não causou aumento de produção de massa verde, com exceção dos ensaios conduzidos em São Simão (quadros 1 e 3). Todavia, nesses tratamentos a quantidade de massa verde incorporada foi pequena para que houvesse efeito da leguminosa como adubo verde, pois, normalmente, para que esse efeito se manifeste, torna-se necessária a incorporação de quantidade bem maior (20 a 40 t/ha). Por outro lado, não houve prejuízo para a produção de milho, como pode ser observado no quadro 2 .

\section{5 - CONCLUSÕES}

Dos resultados podemos concluir:

1) O lablab, em cultura intercalar com a de milho, não tem efeito de adubo verde, uma vez que, ainda quando semeado na mesma época que o milho, a sua produção de massa verde foi pequena.

2) A consorciação do lablab com o milho não prejudicou a produção deste, como demonstram as produções médias contidas no quadro 1 .

3) Para que o lablab tenha desenvolvimento satisfatório, deverá ser plantado na mesma época que o milho.

4) O lablab plantado tardiamente teve o seu desenvolvimento prejudicado, possivelmente devido à concorrência do milho.

\section{DOLICHOS LABLAB L. AS GREEN MANURE, WHEN INTERPLANTED WITH CORN}

\section{SUMMARY}

In five localities in the State of São Paulo the interplanting of Dolichos lablab L. var. 697 with corn was studied. The effects of time and methods of planting of Dolichos and interplanting at different proportions of Dolichos and corn on the production of corn was investigated.

Interplanting Dolichos and corn and the incorporation of Dolichos did not have any influence on corn production.

Dolichos can be planted from October to February and it produces more green matter when planted in October that is at the same time as corn, than later. 


\section{LITERATURA CITADA}

1. MASCARENHAS, H. A. A.; MIYASAKA, S.; LOVADINI, L. A. C. e outros. Efeito da adubação verde do feijoeiro "da sêca", com Crotalaria juncea L., empregando-se tôda a vegetação ou retirando-se do campo as hastes despojadas de suas folhas. Bragantia 26:219-234, 1967.

2. MIYASAKA, S.; FREIRE, E. S.; MASCARENHAS, H. A. A. e outros. Efeito da adubação verde com uma gramínea e quatro leguminosas sôbre a prođução do feijoeiro "da sêca", em terra-roxa-misturada. Bragantia 25:277-290, 1966.

3. - MASCARENHAS, H. A. A.; FREIRE, E. S. e outros. Efeito de NP e $\mathrm{K}$ e de uma mistura de microelementos em terra roxa-misturada prèviamente tratada ou não com calcário dolomítico e adubação verde com labelabe. Bragantia 26:161-180, 1967.

4. NEME, N. A. Ensaio comparativo de adubos verdes. In: Relatório da Seção de Leguminosas, 1958/59. Campinas Instituto Agronômico, 1859

p. 6-10. (Não publicado)

5. SERVIÇO NACIONAL DE PESQUISAS AGRONÓMICAS. Comissão de Solos. Levantamento de reconhecimento dos solos do Estado de São Paulo. Rio de Janeiro, Ministério da Agricultura, 1960. 634p. (Boletim 12) 